$\frac{12}{6}-16-97950$

\title{
An Analytical Model for Predicting Transport in a Coupled Vadose/Phreatic System
}

\section{MASTER}

Environmental Assessment Division Argonne National Laboratory

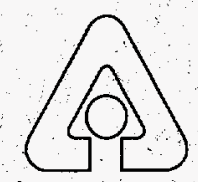

Operated by The University of Chicago, under Contract W-31-109-Eng-38, for the United States Department of Energy 


\section{Argonne National Laboratory}

Argonne National Laboratory, with facilities in the states of Ilinois and Idaho, is owned by the United States Government, and operated by the University of Chicago under the provisions of a contract with the Department of Energy.

This technical memo is a product of Argonne's Environmental Assessment Division (EAD). For information on the divișion's scientific and engineering activities, contact:

Director, Environmental Assessment Division

Argonne National Laboratory

Argonne, llinois 60439-4815

Telephone (630) 252-3107

Presented in this technical memo are preliminary results of ongoing work or work that is more limited in scope and depth than that described in formal reports issued by the EAD.

Publishing support services were provided by Argonne's Information and Publishing Division (for more information, see ÍPD's home page: http://uww.ipd.anl:gov/)

\section{Disclaimer}

This report was prepared as an account of work sponsored by an agency of the United States Government. Neither the United States Government nor any agency thereof, nor any of their employees, makes any warranty, express or implied, or assumes any legal liability or responsibility for the accuracy, completeness, or usefulness of any information, apparatus, product, or process disclosed, or represents that its use would not infringe privately owned rights. Reference herein to any specific commercial product, process, or service by trade name, trademark, manufacturer, or otherwise, does not necessarily constitute or imply its endorsement, recommendation, or favoring by the United States Government or any agency thereof. The views and opinions of authors expressed herein do not necessarily state or reflect those of the United States Government or any agency thereof.

Reproduced directly from the best available copy.

Available to DOE and DOE contractors from the Office of Scientific and Technical Information, P.O. Box 62, Oak Ridge, TN 37831; prices available from (423) $576-8401$.

Available to the public from the National Technical Information Service, U.S. Department of Commerce, 5285 Port Royal Road, Springfield, VA 22161. 


\section{An Analytical Model for Predicting Transport in a Coupled Vadose/Phreatic System}

by D. Tomasko

Environmental Assessment Division,

Argonne National Laboratory, 9700 South Cass Avenue, Argonne, Illinois 60439

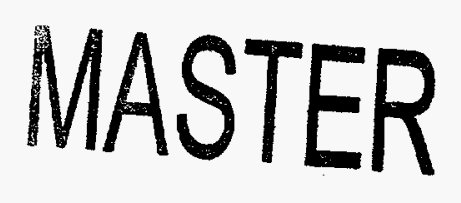

May 1997

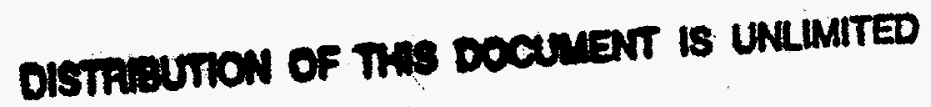

Work sponsored by United States Department of Energy, Office of Facilities, Office of Nuclear Energy, Science and Technology 


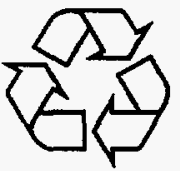

This report is printed on recycled paper. 


\section{DISCLAMMER}

Portions of this document may be illegible in electronic image products. Images are produced from the best available original document. 


\section{CONTENTS}

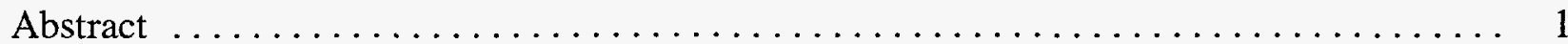

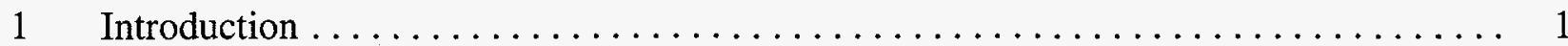

2 One-Dimensional Contaminant Transport $\ldots \ldots \ldots \ldots \ldots \ldots \ldots \ldots \ldots \ldots$

3 Coupled Transport Equations $\ldots \ldots \ldots \ldots \ldots \ldots \ldots \ldots \ldots \ldots \ldots \ldots \ldots$

4 Numerical Inversion of the Coupled Transport Equation $\ldots \ldots \ldots \ldots \ldots \ldots \ldots \ldots$

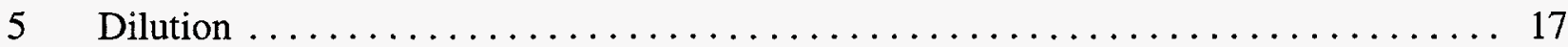

$6 \quad$ Model Verification $\ldots \ldots \ldots \ldots \ldots \ldots \ldots \ldots \ldots \ldots \ldots \ldots \ldots \ldots \ldots$

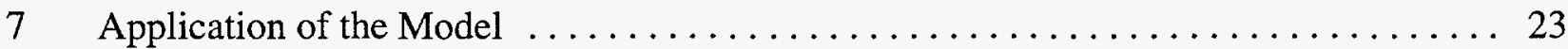

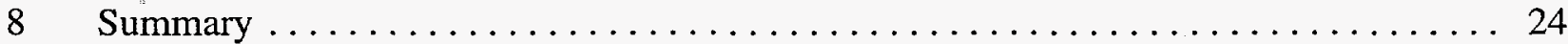

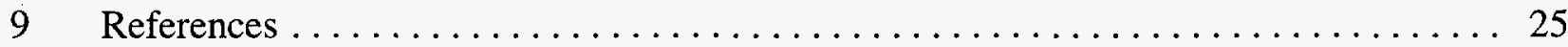

\section{FIGURES}

1 Simulation of a Square-Wave Source Using the Stehfest Algorithm . . . . . . . 13

2 Simulation of a Square-Wave Source Using the Coupled Transport Model $\ldots \ldots \ldots 20$

3 Breakthrough Curve for the Vadose Zone Using the Coupled Transport Model . . . . . 20

4 Breakthrough Curve for the Saturated Zone Using the Analytical Solution . . . . . . 21

5 Difference in Breakthrough Curves between the Coupled Transport Model

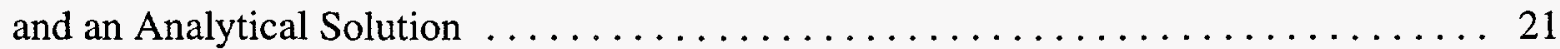

6 Combined Breakthrough Curve for the Coupled Transport Model $\ldots \ldots \ldots \ldots \ldots 22$ 


\title{
AN ANALYTICAL MODEL FOR PREDICTING TRANSPORT IN A COUPLED VADOSE/PHREATIC SYSTEM
}

by

David Tomasko

\begin{abstract}
A simple analytical model is presented for predicting the transport of a contaminant in both the unsaturated (vadose) and saturated (phreatic) zones following a surficial spill. The model incorporates advection, dispersion, adsorption, and first-order decay in both zones and couples the transport processes at the water table. The governing equation is solved by using the method of Laplace transforms, with numerical inversion of the Laplace space equation for concentration. Because of the complexity of the functional form for the Laplace space solution, a numerical methodology using the real and imaginary parts of a Fourier series was implemented. To reduce conservatism in the model, dilution at the water table was also included. Verification of the model is demonstrated by its ability to reproduce the source history at the surface and to replicate appropriate one-dimensional transport through either the vadose or phreatic zone. Because of its simplicity and lack of detailed input data requirements, the model is recommended for scoping calculations.
\end{abstract}

\section{INTRODUCTION}

Calculations are frequently required to evaluate the concentration of a radioactive or degrading contaminant downgradient of a surficial spill. For this report, the contaminant is assumed to follow a path that originates at the location of the spill on the ground surface, moves vertically downward through an unsaturated (vadose) zone, mixes with initially clean water in an unconfined (phreatic) aquifer, moves horizontally through the unconfined aquifer in a direction consistent with the natural flow system, and ultimately ends at the location of an extraction well.

Transport of the radionuclide through the vadose zone is conservatively modeled as a one-dimensional vertical process in which the seepage velocity of the solute is assumed to be equal to the saturated hydraulic conductivity of the least permeable soil horizon or the annual recharge, 
depending on which is smaller. This process is governed by advection, dispersion, adsorption, and radioactive decay (Freeze and Cherry 1979).

At the water table, the vertically moving contaminated pore water in the vadose zone mixes with initially clean water moving laterally in an unconfined aquifer. Mixing is assumed to occur instantaneously across the thickness of the saturated zone. Once in the unconfined aquifer, the contaminant is transported horizontally while again undergoing advection, dispersion, adsorption, and first-order decay. The center of mass of the contaminant distribution moves at the actual groundwater velocity (Darcy velocity divided by the effective porosity of the saturated porous medium [Freeze and Cherry 1979]).

This report details the development and verification of a one-dimensional model that couples the vertical and horizontal transport processes by using the contaminant breakthrough curve for the vadose zone at the water table as a time-dependent boundary condition for transport in the unconfined aquifer. Use of this model is recommended for scoping calculations in which little sitespecific information is available. 


\section{ONE-DIMENSIONAL CONTAMINANT TRANSPORT}

Numerous analytical solutions have been developed for one-dimensional transport in either the vadose or phreatic zones (Ogata and Banks 1961; Javandel et al. 1984). In either case, the basic governing equation for contaminant transport can be written as

$$
\frac{\partial C}{\partial t}=D \frac{\partial^{2} C}{\partial Z^{2}}-V \frac{\partial C}{\partial Z}+\frac{\rho_{b}}{\Phi} \frac{\partial C_{s o r b}}{\partial t}-\lambda C
$$

where the terms on the right hand side of the equation represent dispersion, advection, adsorption, and decay, respectively. Other parameters in Equation 1 include

$$
\begin{aligned}
\mathrm{C} & =\text { contaminant concentration in groundwater, } \\
\mathrm{C}_{\text {sorb }}= & \text { mass of the chemical constituent adsorbed on the solid part of the } \\
& \text { porous medium per unit mass of solids, } \\
\mathrm{t} & =\text { time, } \\
\mathrm{D} & =\text { dispersion coefficient, } \\
\mathrm{Z} & =\text { spatial coordinate, } \\
\mathrm{V} & =\text { seepage velocity, } \\
\Phi & =\text { porosity or water content of the porous medium, and } \\
\lambda & =\text { constant for first-order decay given by: } \\
\lambda &
\end{aligned}
$$

where $t_{1 / 2}$ is the degradation half-life of the contaminant. 
By applying the chain rule for derivatives, the adsorption term in Equation 1 can be written as

$$
\frac{\rho_{b}}{\Phi} \frac{\partial C_{s o r b}}{\partial t}=-\frac{\rho_{b}}{\Phi} \frac{\partial C_{\text {sorb }}}{\partial C} \frac{\partial C}{\partial t}
$$

Results of adsorption studies indicate that for many constituents the following relationship holds (Freeze and Cherry 1979):

$$
C_{\text {sorb }}=K_{d} C^{n}
$$

where $\mathrm{K}_{\mathrm{d}}$ is the contaminant distribution coefficient (mass of solute on the solid phase per unit mass of solid phase divided by the mass of solute per unit volume of solvent), and $\mathrm{n}$ is a chemical-specific parameter associated with the constituent of interest.

For the present study, the sorption reactions are considered to be fast and reversible, and the value of $n$ is 1. Under these conditions, Equation 4 defines the linear Freundlich isotherm. Performing the differentiation in Equation 3 on the linear Freundlich isotherm produces the result that

$$
\frac{\partial C_{s o r b}}{\partial C}=K_{d}
$$

Substituting Equation 5 into Equation 1 produces the following advection/dispersion equation:

$$
\frac{\partial C}{\partial t}=\frac{D}{R} \frac{\partial^{2} C}{\partial Z^{2}}-\frac{V}{R} \frac{\partial C}{\partial Z}-\lambda C
$$

where $\mathrm{R}$ is given by the expression

$$
R=1+\frac{\rho_{b} K_{d}}{\Phi}
$$


Because use of the linear Freundlich isotherm for adsorption effectively decreases the transport velocity of the contaminant in Equation 6, $\mathrm{R}$ is known as the retardation factor (Freeze and Cherry 1979).

The dispersion coefficient, D, in Equations 1 and 6 is often given by the expression (Bear 1972)

$$
D=\alpha V
$$

where the dispersivity, $\alpha$, is scale dependent (Lallemand-Barres and Peaudecerf 1978); that is,

$$
\alpha=0.1 L
$$

where $\mathrm{L}$ is the separation distance from the source to a point of interest (water table or extraction well).

Because Equation 6 is first order in time and second order in space, an initial condition and two boundary conditions must be specified. For simplicity, the initial concentration in the groundwater is set to zero for the calculational domain; that is,

$$
C(Z, t=0)=0.0 \text {. }
$$

If the groundwater is currently contaminated, this condition can be modified according to some given spatial distribution.

Because Equation 6 is second-order in space, two boundary conditions must be imposed. The first boundary condition specifies that the contaminant concentration goes to zero as $\mathrm{Z}$ approaches infinity. The second boundary condition establishes the contaminant concentration at $\mathrm{Z}=0$. For a spill, the contaminant concentration at $\mathrm{Z}=0$ can be treated like a square wave in time; that is, the concentration at $Z=0$ is zero until time $t=0$, at which point the concentration becomes $\mathrm{C}_{0}$. The concentration stays at $\mathrm{C}_{0}$ for a duration equal to $\Delta \mathrm{t}$, at which time it returns to and stays at zero. Mathematically, the square-wave source can be described with the relationship

$$
\frac{C}{C_{0}}=U(t-0)-U(t-\Delta t)
$$


where $\mathrm{U}$ is the unit function (Kreyszig 1967) given by

$$
U(t)=0 \text { for } \mathrm{t}<0
$$

and

$$
U(t)=1 \text { for } t \geq 0 .
$$

Application of the Laplace transform method (Kreyszig 1967) to Equation 6 and the initial and boundary conditions produces a homogeneous, second-order, ordinary differential equation, whose solution in Laplace space is given by

$$
\frac{\bar{C}}{C_{0}}=\frac{1}{S}\left(1-e^{\Delta t S}\right) e^{\frac{V Z}{2 D}} e^{-\sqrt{\frac{V^{2} Z^{2}}{4 D^{2}}+\frac{R \lambda Z^{2}}{D}+\frac{S Z^{2} R}{D}}}
$$

In Equation 14, $\mathrm{S}$ is the Laplace variable and $\overline{\mathrm{C}}$ represents the concentration in Laplace space.

Equation 14 can be inverted using the following relationship presented by Ditkin and Prudnikov (1967):

$$
L^{-1}\left[\frac{e^{-\sqrt{A(B+S)}}}{S}\right]=\frac{1}{2}\left[e^{-\sqrt{A B}} \operatorname{ERFC}\left(\frac{1}{2} \sqrt{\frac{A}{t}}-\sqrt{B t}\right)+e^{\sqrt{A B}} \operatorname{ERFC}\left(\frac{1}{2} \sqrt{\frac{A}{t}}+\sqrt{B t}\right)\right]
$$

where $\mathrm{L}^{-1}$ denotes the inverse transform, along with the following shift identity for Laplace transforms (Hildebrand 1976):

$$
e^{-\Delta t s} f(S)=L[f(t-\Delta t) H(t-\Delta t)]
$$

where $\mathrm{H}$ is the Heavside function (Hildebrand 1976) such that

$$
H(t-\Delta t)=0 \text { for } \mathrm{t}<\Delta \mathrm{t}
$$

and

$$
H(t-\Delta t)=1 \text { for } \mathrm{t} \geq \Delta \mathrm{t}
$$


ERFC in Equation 15 is the complementary error function given by Hildebrand (1976) as

$$
\operatorname{ERFC}(\gamma)=1-\operatorname{ERF}(\gamma)=1-\frac{2}{\sqrt{\pi}} \int_{0}^{\gamma} e^{-\lambda^{2}} d \lambda
$$

Performing the inversion process described above yields the following analytical solution for the relative contaminant concentration (concentration of contaminant at time $t$ and spatial coordinate $\mathrm{Z}$ divided by the initial concentration of the contaminant in the spill), $\mathrm{C} / \mathrm{C}_{0}$, in either the vadose or phreatic zones (Tomasko 1992):

$$
\begin{aligned}
& \frac{C}{C_{0}}=\frac{e^{\frac{V Z}{2 D}}}{2}\left[e^{-\sqrt{\frac{Z^{2}}{D}\left(\frac{V^{2}}{4 D}+\lambda\right)}} \operatorname{ERFC}\left(\frac{1}{2} \sqrt{\frac{R Z^{2}}{D t}}-\sqrt{\left(\frac{V^{2}}{4 D R}+\frac{\lambda}{R}\right)} t\right)\right. \\
& \left.+e^{\sqrt{\frac{Z^{2}}{D}\left(\frac{V^{2}}{4 D}+\lambda\right)}} \operatorname{ERFC}\left(\frac{1}{2} \sqrt{\frac{R Z^{2}}{D t}}+\sqrt{\left(\frac{V^{2}}{4 D R}+\frac{\lambda}{R}\right) t}\right)\right] \\
& -\frac{e^{\frac{V Z}{2 D}}}{2} H(t-\Delta t)\left[e^{-\sqrt{\frac{Z^{2}}{D}\left(\frac{V^{2}}{4 D}+\lambda\right)}}\right. \\
& \times \operatorname{ERFC}\left(\frac{1}{2} \sqrt{\frac{R Z^{2}}{D(t-\Delta t)}}-\sqrt{\left(\frac{V^{2}}{4 D R}+\frac{\lambda}{R}\right)(t-\Delta t)}\right) \\
& \left.+e^{\sqrt{\frac{Z^{2}}{D}\left(\frac{V^{2}}{4 D}+\lambda\right)}} \operatorname{ERFC}\left(\frac{1}{2} \sqrt{\frac{R Z^{2}}{D(t-\Delta t)}}+\sqrt{\left(\frac{V^{2}}{4 D R}+\frac{\lambda}{R}\right)(t-\Delta t)}\right)\right]
\end{aligned}
$$

Equation 20 has been used to predict the concentration of degradable contaminants in both the vadose and saturated zones (e.g., Tomasko 1992; Butler et al. 1994; Johnson et al. 1994; 
Tomasko 1994; and Tomasko 1995). Although Equation 20 can be used to predict contaminant concentrations for one-dimensional transport in either the vadose or phreatic zones, it cannot be used to simulate a coupled vadose/phreatic zone system. Such modeling has typically been performed with more complex numerical computer models, such as SUTRA (Voss 1984) and TRACR3D (Travis and Birdsell 1991). These models typically require extensive input data that are both accurate and site specific.

In the present study, the simple one-dimensional analytical approach discussed above is extended to include coupling between the vadose and phreatic zones. 


\section{COUPLED TRANSPORT EQUATIONS}

For the coupled transport model, solute transport in the vadose zone is represented with the following equation:

$$
\frac{\partial C_{v}}{\partial t}=\frac{D_{v}}{R_{v}} \frac{\partial^{2} C_{v}}{\partial Z^{2}}-\frac{V_{v}}{R_{v}} \frac{\partial C_{v}}{\partial Z}-\lambda_{v} C_{v}
$$

where subscript $v$ denotes the vadose zone. For radionuclide decay, the decay constant, $\lambda_{v}$, is independent of saturation. If the contaminant's decay constant is a function of saturation (e.g., firstorder decay of a nonaqueous phase liquid [NAPL], the decay constant could be different for the two zones of the model). Adsorption along the flow path is simulated through the retardation parameter, $\mathrm{R}_{\mathrm{v}}$, where

$$
R_{v}=1+\frac{\rho_{b v} K_{d v}}{\Phi_{v}}
$$

In the saturated zone, transport in the coupled model is horizontal and governed by the following expression:

$$
\frac{\partial C_{s}}{\partial t}=\frac{D_{s}}{R_{s}} \frac{\partial^{2} C_{s}}{\partial X^{2}}-\frac{V_{s}}{R_{s}} \frac{\partial C_{s}}{\partial X}-\lambda_{s} C_{s}
$$

where subscript $\mathrm{s}$ denotes the saturated zone.

In Equation 23, $\mathrm{V}_{\mathrm{s}}$ is the actual groundwater velocity (Freeze and Cherry 1979) given by the expression

$$
V_{s}=-\frac{K_{s} \nabla h}{\Phi_{s}}
$$

where $\mathrm{K}_{\mathrm{s}}$ is the hydraulic conductivity and $\Phi_{\mathrm{s}}$ is the effective porosity of the saturated zone, and $\nabla \mathrm{h}$ is the hydraulic gradient (change in water level with distance) present. 
As for transport through the vadose zone, advection, dispersion, adsorption, and first-order decay are specifically included in Equation 23. Adsorption is again incorporated by using a linear Freundlich isotherm and a retardation factor given by

$$
R_{s}=1+\frac{\rho_{b s} K_{d s}}{\Phi_{s}}
$$

Equation 21 can be solved to estimate the contaminant concentration in the vadose zone. The solution to this equation for a step-function source is given by Equation 20 . The contaminant concentration in the saturated zone can then be estimated by solving Equation 23 . As for the vadose zone, an initial condition and two boundary conditions are required to solve the second-order partial differential equation. For the saturated zone, the initial contaminant concentration is again set equal to zero, and the concentration is assumed to go to zero as the lateral transport distance, $\mathrm{X}$, approaches infinity. At $X=0$ (the point where the vadose and saturated zones meet directly below the spill), the concentration is given by Equation 20 with $Z$ set equal to the depth of the water table (i.e., $Z=Z_{t}$ ). By incorporating this boundary condition, transport in the vadose and phreatic zones are coupled.

After defining the initial and boundary conditions for the transport equation in the saturated zone, the method of Laplace transforms is again used to transform the partial differential equation to a second-order ordinary differential equation. The solution of this equation in Laplace space for the initial and boundary conditions is given by

$$
\frac{\bar{C}}{C_{0}}=\frac{1}{S}\left(1-e^{-\Delta t S}\right) C_{1} e^{-\sqrt{C_{2}+C_{3} S}} e^{-\sqrt{C_{4}+C_{5} S}}
$$

where

$$
\begin{gathered}
C_{1}=e^{\frac{V_{v} Z_{t}}{2 D_{v}}} e^{\frac{V_{s} X}{2 D_{s}}} \\
C_{2}=\frac{V_{v}^{2} Z_{t}^{2}}{4 D_{v}^{2}}+\frac{R_{v} \lambda_{v} Z_{t}^{2}}{D_{v}} \\
C_{3}=\frac{Z_{t}^{2} R_{v}}{D_{v}}
\end{gathered}
$$




$$
C_{4}=\frac{V_{s}^{2} X^{2}}{4 D_{s}^{2}}+\frac{R_{s} \lambda_{s} Z^{2}}{D_{s}}
$$

and

$$
C_{5}=\frac{X^{2} R_{s}}{D_{s}}
$$

Because of the complex functional form of Equation 26, no simple analytical inversion of the Laplace space solution was found. This equation can, however, be inverted using numerical methods. A discussion of this methodology is presented in Section 4. 


\section{NUMERICAL INVERSION OF THE COUPLED TRANSPORT EQUATION}

Because analytical inversion of Laplace space equations can be extremely difficult, a number of numerical methods have been developed to find the inverses (real time and space solutions) (Davies and Martin 1979). Of these methods, the Stehfest algorithm (Stehfest 1970a,b) is one of the best known; however, in the presence of sharp amplitude discontinuities (such as those that would occur for a step-function source term), this method produces spurious results (Davies and Martin 1979) as demonstrated in Figure 1, where the Stehfest algorithm was used to predict the behavior of a square wave source at $Z=0$ (Tomasko 1990).

Much better computational accuracy can be obtained by using the real portion of a Fourier series to invert the Laplace space solution (Dubner and Abate 1968). This method is particularly well-suited for functions that have abrupt amplitude transitions. An improved version of this methodology was developed by Crump (1976), who incorporated both the real and imaginary terms of a Fourier series in the inversion process:

$$
\begin{aligned}
f(t)= & \frac{e^{c t}}{2 T_{m}}\left(\left\{\frac{1}{2} F(c)+\sum_{K=1}^{\infty}\left[\operatorname{Re} F\left(c+\frac{K \pi i}{2 T_{m}}\right) \cos \left(\frac{K \pi t}{2 T_{m}}\right)\right.\right.\right. \\
& \left.\left.\left.-\operatorname{Im} F\left(c+\frac{K \pi i}{2 T_{m}}\right) \sin \left(\frac{K \pi t}{2 T_{m}}\right)\right]\right\}\right)
\end{aligned}
$$

where

$$
\begin{aligned}
\mathrm{f}(\mathrm{t}) & =\text { concentration as a function of } \mathrm{t} \text { and } \mathrm{Z}, \\
\mathrm{T}_{\mathrm{m}} & =\text { maximum time of the calculation, } \\
\mathrm{F}(\mathrm{c}) & =\text { Laplace space solution as a function of } \mathrm{c}, \\
\mathrm{Re} & =\text { real part of the complex function, } \\
\mathrm{Im} & =\text { imaginary part of the complex function, and } \\
\mathrm{c} & =5 / \mathrm{T}_{\mathrm{m}} .
\end{aligned}
$$




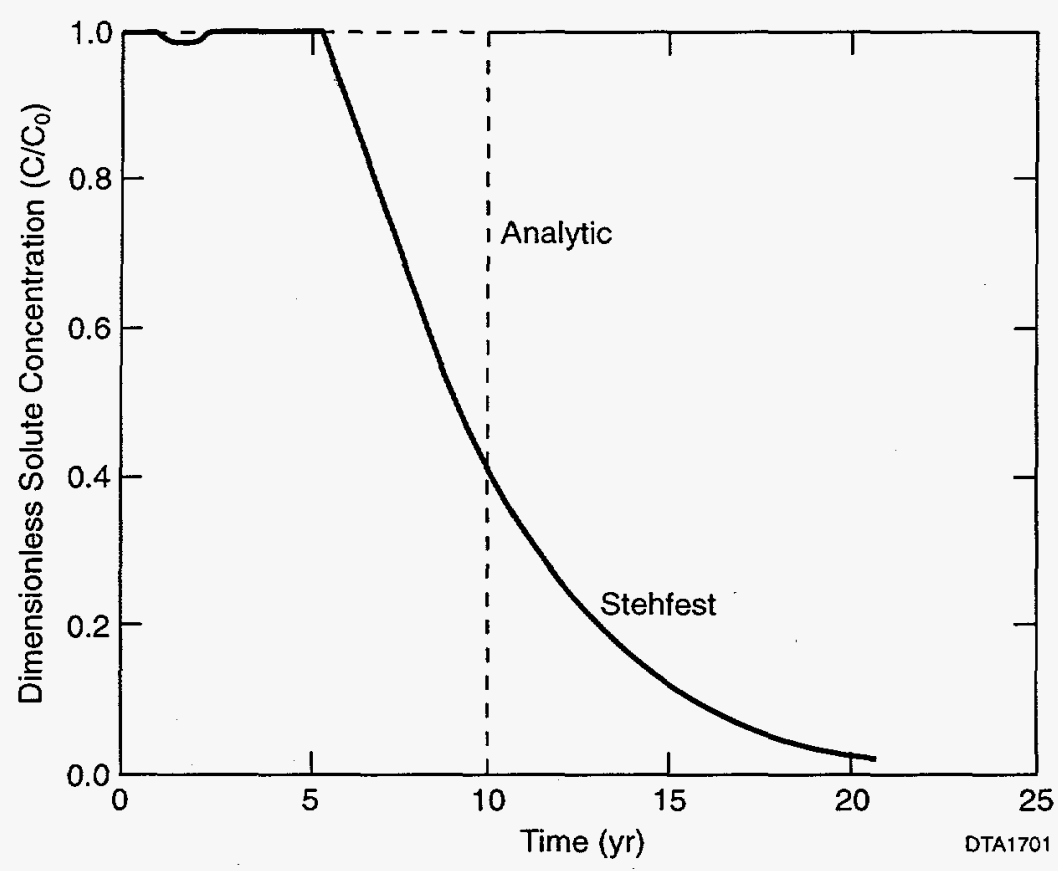

FIGURE 1 Simulation of a Square-Wave Source Using the Stehfest Algorithm (Source: Tomasko 1990)

In implementing the numerical inversion process, the Laplace variable, $\mathrm{S}$, in Equation 26 is replaced with its complex counterpart:

$$
S=c+d i
$$

where

$$
d=\frac{K \pi}{2 T_{m}}
$$

and

$$
i=\sqrt{-1}
$$

In order to implement the Crump algorithm for the coupled transport model, $F(c)$ and $F(c+d i)$ must be formed for Equation 32. Using Equation 26, $F(c)$ is simply given by the relation 


$$
F(c)=\frac{1}{c}\left(1-e^{-\Delta t c}\right) C_{1} e^{-\sqrt{C_{2}+C_{3} c}} e^{-\sqrt{C_{4}+C_{5} c}}
$$

where $\mathrm{C}_{1}$ through $\mathrm{C}_{5}$ were defined in Equations 27-31.

$\mathrm{F}(\mathrm{c}+\mathrm{di})$ can be formed by substituting Equation 33 into Equation 26 . The result is given by

$$
F(c+d i)=\frac{c-d i}{c^{2}+d^{2}}\left[1-e^{-\Delta t(c+d i)}\right] C_{1} e^{-\sqrt{C_{2}+C_{3}(c+d i)}} e^{-\sqrt{C_{4}+C_{5}(c+d i)}}
$$

where the denominator in the leading term of Equation 26 has been rationalized (Wunsch 1983).

Substitution of Equations 36 and 37 into 32 yields the final equation for numerical inversion with the Crump algorithm:

$$
\begin{aligned}
f(t)= & \frac{e^{c t}}{2 T_{m}}\left(\frac{1}{2}\left(\frac{1-e^{-\Delta t c}}{c} C_{1} e^{-\sqrt{C_{2}+C_{3} c}} e^{-\sqrt{C_{4}+C_{5} c}}\right)\right. \\
& +\sum_{K=1}^{\infty}\left\{\operatorname{Re}\left[\frac{Z_{1}}{c^{2}+d^{2}} Z_{2} C_{1} e^{-T_{1}} e^{-T_{3}} Z_{3} Z_{4} \cos \left(\frac{K \pi t}{2 T_{m}}\right)\right]\right. \\
& -\operatorname{Im}\left[\frac{\left.\left.\left.Z_{1} Z_{2} C_{1} e^{-T_{1}} e^{-T_{3}} Z_{3} Z_{4} \sin \left(\frac{K \pi t}{2 T_{m}}\right)\right]\right\}\right)}{c^{2}+d^{2}}\right)
\end{aligned}
$$

where

$$
\begin{gathered}
Z_{1}=c-d i \\
Z_{2}=P_{1}+P_{2} i
\end{gathered}
$$




$$
\begin{aligned}
Z_{3} & =\cos \left(T_{2}\right)-i \sin \left(T_{2}\right) \\
Z_{4} & =\cos \left(T_{4}\right)-i \sin \left(T_{4}\right) \\
T_{1} & =\frac{\sqrt{r_{1}+\sqrt{r_{1}^{2}+r_{2}^{2}}}}{\sqrt{2}} \\
T_{2} & =\frac{\sqrt{-r_{1}+\sqrt{r_{1}^{2}+r_{2}^{2}}}}{\sqrt{2}} \\
P_{1} & =1-e^{-\Delta t c} \cos (\Delta t d) \\
P_{3} & =\frac{\sqrt{r_{3}+\sqrt{r_{3}^{2}+r_{4}^{2}}}}{\sqrt{2}} \\
T_{3} & \sqrt{-r_{3}+\sqrt{r_{3}^{2}+r_{4}^{2}}}
\end{aligned}
$$

$$
\begin{gathered}
r_{2}=C_{3} d \\
r_{3}=C_{4}+C_{5} c
\end{gathered}
$$


and

$$
r_{4}=C_{5} d
$$

In performing the numerical inversion, terms of the form

$$
e^{\sqrt{r_{1}+r_{2} i}}
$$

are computationally inconvenient. Such terms were, however, managed by using the following transformation from Wunsch (1983):

$$
e^{\sqrt{X+i Y}}=e^{a+i b}
$$

where

$$
a=\frac{\sqrt{X+\sqrt{X^{2}+Y^{2}}}}{\sqrt{2}}
$$

and

$$
b=\frac{\sqrt{-X+\sqrt{X^{2}+Y^{2}}}}{\sqrt{2}}
$$

In addition, the relationship

$$
e^{a+i b}
$$

was conveniently managed by using the following property of the complex exponential function (Wunsch 1983):

$$
e^{a+i b}=e^{a}[\cos (b)+i \sin (b)]
$$

In order to evaluate Equation 38, a computer program was written. The indicated summation was performed until the fractional change in the sum was less than or equal to $10^{-6}$. This level of accuracy typically required between 1,000 and 2,000 terms in the expansion. 


\section{DILUTION}

In the coupled transport model, contaminated pore water in the vadose zone mixes instantaneously and across the full thickness of the phreatic zone after reaching the saturated groundwater aquifer. This mixing reduces the contaminant concentration. The ratio of contaminant concentration in the vadose zone to that in the saturated groundwater can be defined as the dilution factor for the process, $\mathrm{D}_{\mathrm{f}}$. Dividing the contaminant concentration in the vadose zone by this factor provides an estimate of the concentration in the groundwater aquifer directly below the spill.

The dilution process can be expressed by the following relationship (EPA 1989):

$$
D_{f}=\frac{Q_{v}+Q_{h}}{Q_{v}}
$$

where

$$
\begin{aligned}
& \mathrm{Q}_{\mathrm{v}}=\text { volumetric flux in the vertical direction in the vadose zone and } \\
& \mathrm{Q}_{\mathrm{h}}=\text { volumetric flux in the horizontal direction in the phreatic zone. }
\end{aligned}
$$

The vertical volumetric flux of Equation $59, Q_{Y}$, can be written in the following form for a rectangular control volume:

$$
Q_{v}=I A_{v} \Phi_{v}=I L_{d} W \Phi_{v}
$$

where

$$
\begin{aligned}
L_{d} & =\text { length of the control volume parallel to the direction of groundwater flow, } \\
I & =\text { rate of infiltrating precipitation, } \\
\Phi_{v} & =\text { effective porosity of the vadose zone, and } \\
W & =\text { transverse width of the control volume. }
\end{aligned}
$$

For analysis, $\mathrm{L}_{\mathrm{d}}$ is equal to the diameter of the spill at the ground surface. 
In the horizontal direction, the volumetric flux, $\mathrm{Q}_{\mathrm{h}}$, of Equation 59, can be written as

$$
Q_{h}=V_{s} A_{e}=V_{d} A_{t}
$$

where

$A_{e}=$ effective cross-sectional area of the saturated aquifer $=A_{t} \Phi_{s}$,

$\mathrm{A}_{\mathrm{t}}=$ total cross-sectional area of the saturated aquifer,

$\Phi_{\mathrm{s}}=$ porosity of the saturated zone, and

$\mathrm{V}_{\mathrm{s}}=$ actual groundwater velocity $=\mathrm{V}_{\mathrm{d}} / \Phi_{\mathrm{s}}$

and $V_{d}$ is the Darcy velocity given by

$$
V_{d}=-K \nabla h
$$

where $\mathrm{K}$ is the hydraulic conductivity of the saturated zone and $\mathrm{\nabla h}$ is its hydraulic gradient (Freeze and Cherry 1979).

$\mathrm{Q}_{\mathrm{h}}$ can thus be written as

$$
Q_{h}=V_{d} T W
$$

where $\mathrm{T}$ is the thickness of the saturated zone.

By using the above definitions, Equation 59 can be rewritten as

$$
D_{f}=\frac{V_{d} T}{I L_{d} \Phi_{v}}+1
$$

In developing Equation 64, infiltrating groundwater outside the area of the spill is assumed to have a negligible effect on the flow and thickness of the saturated zone. This assumption provides a conservative estimate of the dilution by limiting the mixing capability of the phreatic zone to an area directly below the footprint of the spill. 


\section{MODEL VERIFICATION}

As part of the verification process, the coupled transport model was evaluated against known solutions, when possible. Of these known solutions, one of the most critical is the ability of the model to reproduce the step-function source at the top of the unsaturated zone.

Figure 2 shows the results of the coupled transport model for $Z=0$, and a step-function duration of 10 years. The results are very good, and the square wave is replicated. By integrating the curve in Figure 2 and comparing the result to that derived from an analytical calculation, the percentage of mass error can be found. By using the Simpson integration (Thomas 1953), the mass error was less than $0.001 \%$, which is acceptable for this application.

In the second verification test, results from the coupled transport model were compared with the results of the analytical solution given in Equation 20 for a distance of $100 \mathrm{ft}$, a dispersion coefficient of $0.75 \mathrm{ft}^{2} / \mathrm{yr}$, a seepage velocity of $10 \mathrm{ft} / \mathrm{yr}$, a retardation coefficient of 1.0 , a radioactive decay constant of $10^{-7} / \mathrm{yr}$, and a source duration of $10 \mathrm{yr}$. The results of the calculations are shown in Figures 3 and 4 for the coupled transport model and the analytical solution, respectively. For the coupled transport model, the calculations were performed vertically from 0 to $100 \mathrm{ft}$. As indicated, the results are nearly the same. A plot of the percent difference between the two methods is shown in Figure 5. The largest error is less than $0.01 \%$ in the region of the sharpest amplitude discontinuities of the source term, as expected. Identical results were obtained by executing the coupled transport model with a $Z$ equal to 0 and a lateral transport distance of $100 \mathrm{ft}$. Because of the model formulation, symmetric results should be obtained if all other parameters in the calculation are the same except for the point of origin for the source.

If the physical characteristics of the vadose zone and phreatic zone are the same, and a source is introduced at the ground level $(Z=0)$, the solution obtained for the coupled transport model should be the same as that previously obtained if the depth to the water table is set to $50 \mathrm{ft}$ and the lateral transport distance is set to $50 \mathrm{ft}$. The results of this calculation are shown in Figure 6 . As required, the results are identical to those previously obtained.

Varying the other parameters in the coupled transport model (e.g., retardation, dispersion, and the decay constant) produced results similar to those derived from the analytic solution for both transport through a single leg of the model (vadose or phreatic zone) and for dividing the pathway into two equal halves, as done above.

Because the coupled transport model successfully replicated the square-wave source, had very good agreement with results from single-leg analytic solutions, produced symmetric solutions based on the location of the source, and could be overlaid with two equivalent half-paths, verification of the model was deemed adequate. 


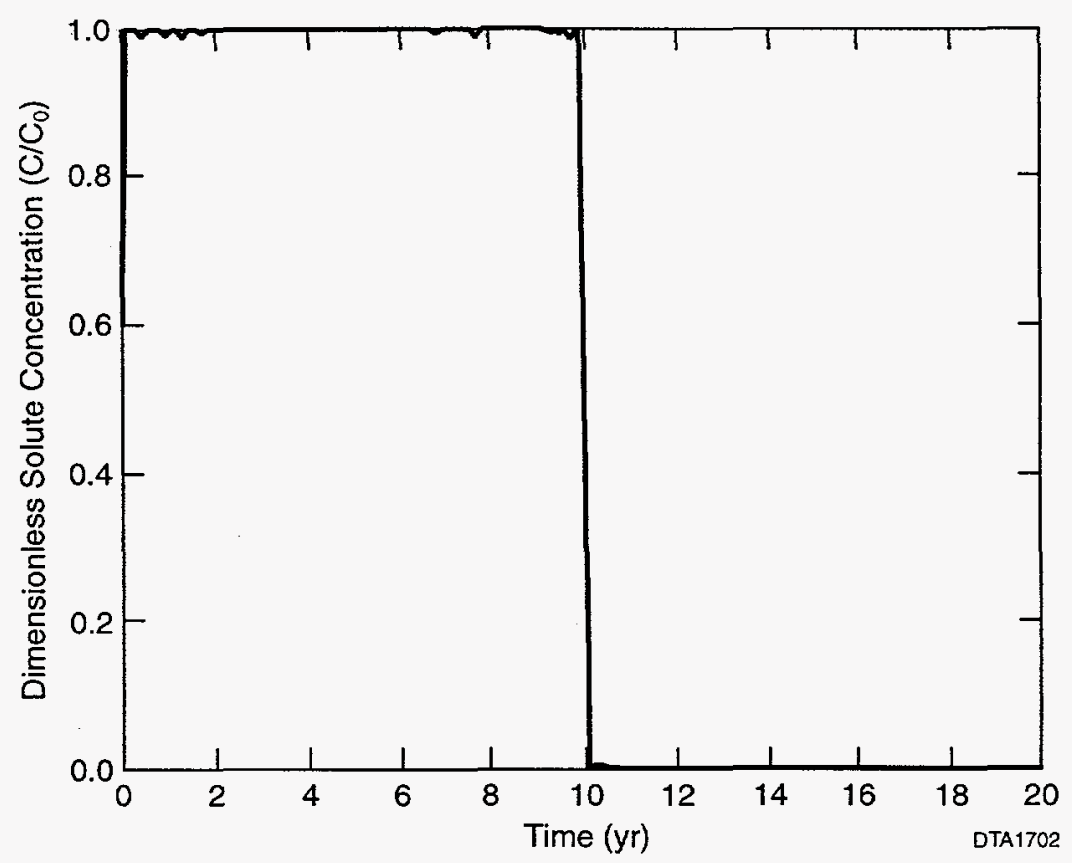

FIGURE 2 Simulation of a Square-Wave Source Using the Coupled Transport Model

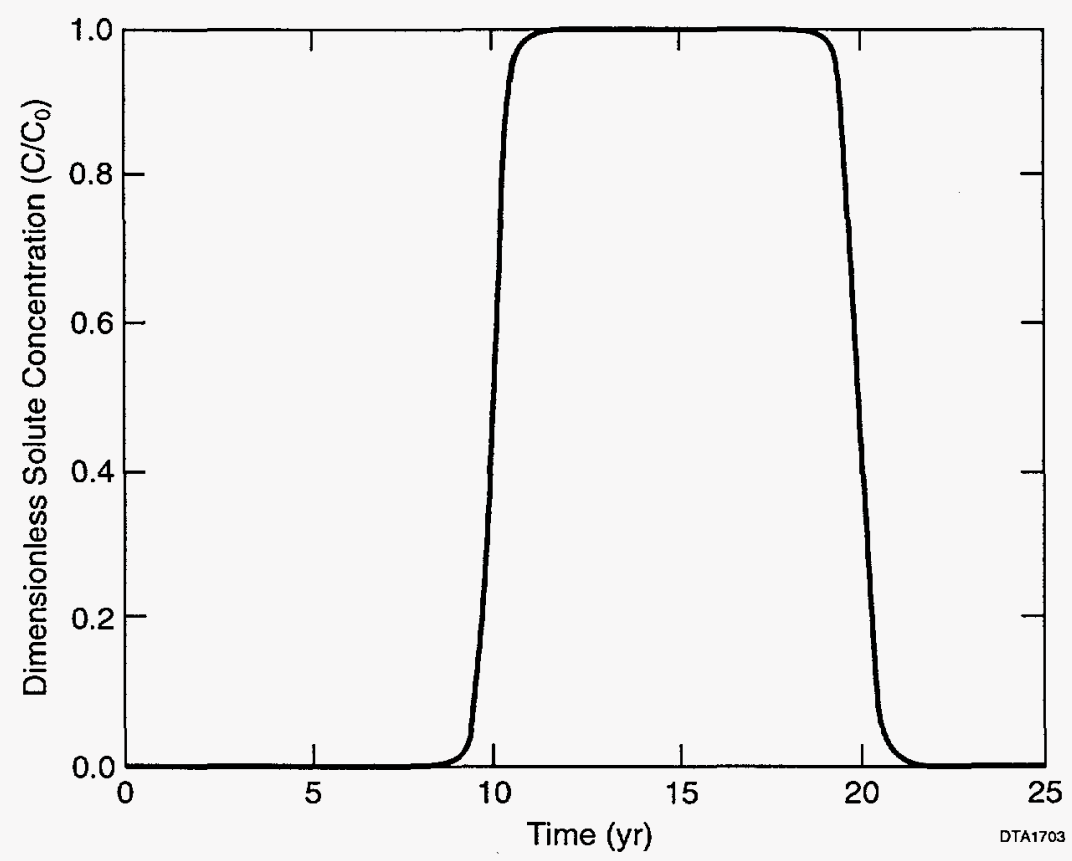

FIGURE 3 Breakthrough Curve for the Vadose Zone Using the Coupled Transport Model $(Z=100 \mathrm{ft}, X=0)$ 


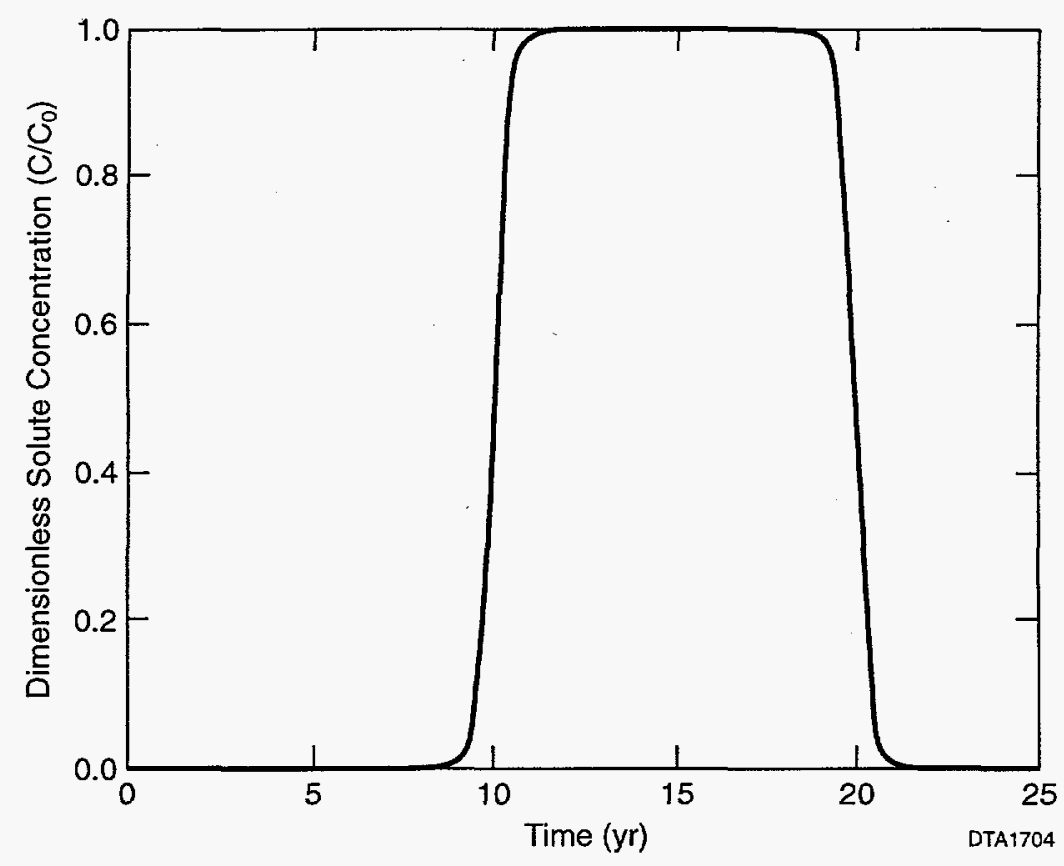

FIGURE 4 Breakthrough Curve for the Saturated Zone Using the Analytical Solution $(Z=0, X=100 \mathrm{ft})$

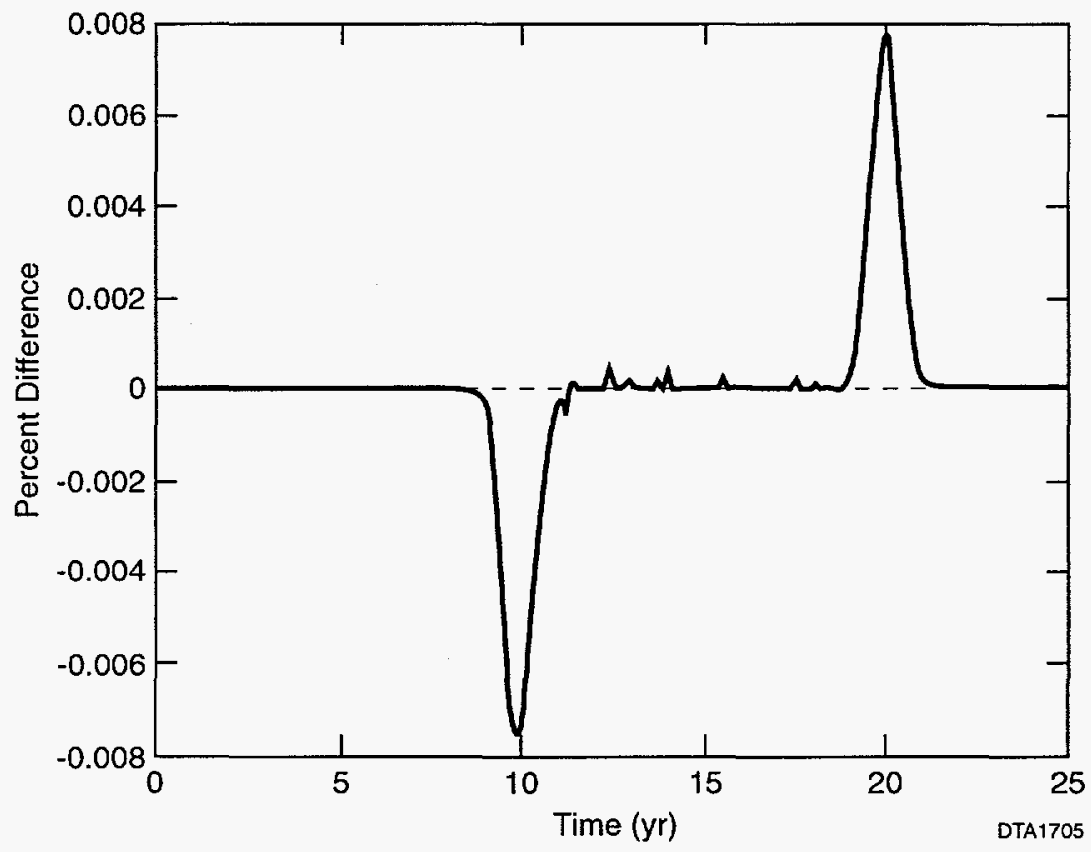

FIGURE 5 Difference in Breakthrough Curves between the Coupled Transport Model and an Analytical Solution 


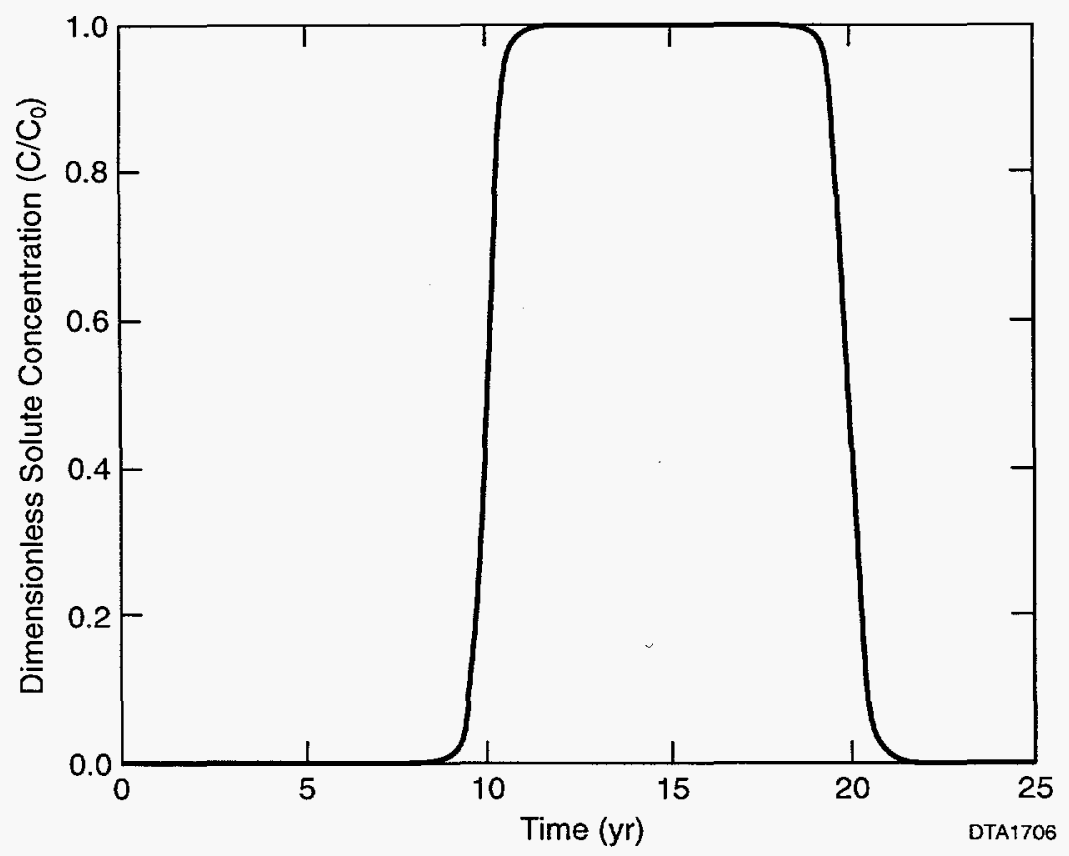

FIGURE 6 Combined Breakthrough Curve for the Coupled Transport Model $(Z=\mathbf{5 0} \mathrm{ft}, X=50 \mathrm{ft}$ ) 


\section{APPLICATION OF THE MODEL}

Equation 38 can be used to calculate relative concentrations downstream of a surficial spill in either the vadose zone or the phreatic zone. As written, Equation 38 provides a dimensionless concentration as a function of time and space. To obtain a dimensional concentration, $\mathrm{C} / \mathrm{C}_{0}$ must be multiplied by the initial contaminant concentration, $\mathrm{C}_{0}$. For simplicity, $\mathrm{C}_{0}$ can be set equal to the solubility of the contaminant of interest or, if known, concentrations from leaching tests (e.g., Toxicity Characteristic Leaching Procedures [TCLP] values [EPA 1994]) can be used directly. Because TCLP or leachate data may not be available, a solubility-limited concentration is recommended because it will produce conservative results (i.e., the concentrations predicted by the model will be greater than those in the field).

If the concentration of the contaminant is only desired for the vadose region, no further calculations are required. If calculations are desired at the location of an extraction well in the saturated zone, however, the dimensional concentration must be reduced by the dilution factor discussed in Section 6 to account for mixing with initially clean water in the aquifer. 


\section{SUMMARY}

This report presented the development of a coupled transport model that can be used to calculate the concentration of a contaminant in both the unsaturated and saturated zones following a surficial spill. The model incorporates advection, dispersion, adsorption, and radioactive decay in both zones and couples the transport process at the water table. The governing one-dimensional partial differential equations for transport are coupled and solved by using the method of Laplace transforms, with numerical inversion of the Laplace space equation for concentration. A numerical methodology was used because of the complexity of the functional form for the Laplace space concentration.

Because the resulting solutions are formulated in terms of relative concentrations, dimensional results require a knowledge of the initial contaminant concentration. If no leaching results are available, conservative results can be obtained by using the solubility of the contaminant as an initial concentration.

Verification of the model was demonstrated by its ability to reproduce a square-wave source at the ground surface and its ability to replicate appropriate one-dimensional transport through either the vadose or phreatic zones.

Because of its simplicity and lack of detailed input data requirements, the coupled transport model is recommended for scoping calculations. 


\section{REFERENCES}

Bear, J., 1972, Dynamics of Fluids in Porous Media, American Elsevier Publishing Company, New York.

Butler, J.P., D. Tomasko, and E.H. Cho, 1994, "Risk-Based Screening Approach for Estimating Groundwater Impacts at Petroleum-Contaminated Sites," Annual Meeting of the Society for Risk Analysis, Baltimore, Md., Dec.

Crump, K.S., 1976, "Numerical Inversion of Laplace Transforms Using A Fourier Series Approximation," Journal of the Association for Computing Machinery, 23(1):89-96.

Davies, B., and B. Martin, 1979, "Numerical Inversion of the Laplace Transform: A Survey and Comparison of Methods," Journal of Computational Physics, 33:1-32.

Ditkin, V.A., and A.P. Prudnikov, 1967, Formulaire pour Le Calcul Operationnel, Masson et Cie, Editeurs, Paris, France, 472 pp.

Dubner, H.; and J. Abate, 1968, "Numerical Inversion of Laplace Transforms by Relating Them to the Finite Fourier Cosine Transform," Journal of the Association for Computing Machinery, $15(1): 115-223$.

Freeze, R.A., and J.A. Cherry, 1979, Groundwater, Prentice-Hall, Inc., Englewood Cliffs, N.J., $604 \mathrm{pp}$.

Hildebrand, F.B., 1976, Advanced Calculus for Applications, Prentice-Hall, Inc., Englewood Cliffs, N.J., 733 pp.

Javandel, I., C. Doughty, and C.F. Tsang, 1984, Groundwater Transport: Handbook of Mathematical Models, American Geophysical Union, Washington, D.C.

Johnson, R., D. Tomasko, D. Blunt, and H. Hartmann, 1994, "Coupling Human Health Risk Assessments with Vadose Zone Modeling," 1994 Groundwater Modeling Conference, Ft. Collins, Colo., Aug.

Kreyszig, E., 1967, Advanced Engineering Mathematics, John Wiley and Sons, New York City, N.Y., 898 pp. 
Lallemand-Barrès, A., and P. Peaudecerf, 1978, Recherche des Relations entre a Valeur de la Dispersivitè Macroscopique d'un Milieu Aquifere, Ses Autres Caractèristiques et les Conditions de Mesure, Bulletin Bureau Geologique Minières, 4-1978:277-284.

Ogata, A., and R.B. Banks, 1961, "A Solution of the Differential Equation of Longitudinal Dispersion in Porous Media," U.S. Geological Survey Professional Paper 411-A.

Stehfest, H., 1970a, “Algorithm 368, Numerical Inversion of Laplace Transforms," Communications of the Association for Computing Machinery, 13(1):47-49.

Stehfest, H., 1970b, "Remark on Algorithm 368, Numerical Inversion of Laplace Transforms," Communications of the Association for Computing Machinery, 13(10):624.

Thomas, G.B., 1953, Calculus and Analytic Geometry, Addison-Wesley Publishing Company, Reading, Mass., 822 pp.

Tomasko, D., 1990, The Effect of a Zero-Concentration Sink on Contaminant Transport and Remedial-Action Designs for the Weldon Spring Quarry, Weldon Spring, Missouri, ANL/EAIS/TM-31, Argonne National Laboratory, Argonne, Ill.

Tomasko, D., 1992, Modeling Vertical and Horizontal Solute Transport for the Weldon Spring Site Remedial Action Project, ANL/EAIS/TM-77, Argonne National Laboratory, Argonne, Ill.

Tomasko, D., 1994, "A Solubility-Limited Leaching and Transport Model for Predicting Nitroaromatic Concentrations at the Water Table," Geological Society of America, Seattle, Wash., Oct.

Tomasko, D., 1995, "An Analytical Model for LNAPL Transport in the Vadose Zone," International Groundwater Management Symposium, San Antonio, Texas, Aug.

Travis, B.J., and K.H. Birdsell, 1991, TRACR3D: A Model of Flow and Transport in Porous Media, Model Description and User's Manual, LA-11798-M, Los Alamos National Laboratory, Los Alamos, N.M.

U.S. Environmental Protection Agency, 1989, Determining Soil Response Action Levels Based on Potential Contaminant Migration to Ground Water: A Compendium of Examples, EPA/540/2-89/057, Office of Emergency and Remedial Response, Washington, D.C.

U.S. Environmental Protection Agency, 1994, Technical Assistance Document for Complying with the TC Rule and Implementing the Toxicity Characteristic Leaching Procedures (TCLP), Washington, D.C. 
Voss, C.I., 1984, SUTRA - Saturated Unsaturated Transport - A Finite-Element Simulation Model for Saturated/Unsaturated, Fluid-Density Dependent Ground-Water Flow with Energy Transport or Chemical Reactive Single-Species Solute Transport, WRI 84-4369, U.S. Geological Survey, Reston, Va.

Wunsch, A.D., 1983, Complex Variables with Applications, Addison-Wesley Publishing Company, Reading, Mass., 439 pp. 
